\title{
Demanda de tração e propriedades físicas de um Argissolo em diferentes manejos e intensidades de tráfego
}

\author{
David Peres da Rosa(1), José Miguel Reichert(2), Marcelo Ivan Mentges ${ }^{(2)}$, Vanderleia Trevisan da Rosa(3), \\ Davi Alexandre Vieira ${ }^{(2)}$ e Dalvan José Reinert(2)
}

\begin{abstract}
(1)Instituto Federal de Educação, Ciência e Tecnologia do Rio Grande do Sul, Campus Sertão, Caixa Postal 21, CEP 99170-000 Sertão, RS. E-mail: david.darosa@sertao.ifrs.edu.br (2)Universidade Federal de Santa Maria, Centro de Ciências Rurais, Departamento de Solos, Avenida Roraima, 1.000, CEP 97105-900 Santa Maria, RS. E-mail: reichert@smail.ufsm.br, marcelomentges@gmail.com, daviperigoti@yahoo.com.br, dalvan@smail.ufsm.br ${ }^{(3)}$ Instituto de Desenvolvimento Educacional do Alto Uruguai, Faculdade de Agronomia, Rua Jacob Gremmelmaier, 215, Bairro Centro, CEP 99900-000, Getúlio Vargas, RS. E-mail: vandetrevisan@gmail.com
\end{abstract}

Resumo - O objetivo deste trabalho foi avaliar o efeito da intensidade de tráfego e do sistema de manejo na demanda de tração de uma haste sulcadora de adubo, e nas propriedades físicas de um Argissolo Vermelho-Amarelo. Os tratamentos foram: semeadura direta com tráfego natural, semeadura direta com tráfego adicional de intensidade de 24,79 $\mathrm{Mg} \mathrm{km} \mathrm{ha}^{-1}$, semeadura direta com tráfego adicional de intensidade de 49,59 $\mathrm{Mg} \mathrm{km} \mathrm{ha}^{-1}$, cultivo mínimo e cultivo mínimo em solo compactado com tráfego de $24,67 \mathrm{Mg} \mathrm{km} \mathrm{ha}^{-1}$. Foram coletados dados de: porosidade total; densidade do solo; resistência mecânica do solo à penetração; e de esforço horizontal, vertical e de tração da haste sulcadora de adubo da semeadora. A subsolagem do cultivo mínimo, utilizada como técnica isolada, não reduziu os efeitos da compactação ocasionados pela intensidade de tráfego de $24,67 \mathrm{Mg} \mathrm{km} \mathrm{ha-1}$. O tráfego afeta a estrutura do solo, sem alterar, porém, a demanda de tração. A mudança da intensidade de tráfego, de 24,79 para 49,59 Mg km ha-1, não ocasionou maiores alterações nas propriedades avaliadas.

Termos de indexação: compactação, cultivo mínimo, densidade do solo, estrutura do solo, semeadura direta, subsolagem.

\section{Draught requirement and physical properties in a Hapludalf at different management and traffic intensity levels}

\begin{abstract}
The objective of this work was to evaluate the effect of traffic intensity and soil management on the draught demand of a fertilizer furrow-opener, and on the physical properties of a Hapludalf. Treatments were: no-tillage with natural traffic, no-tillage with traffic intensity of $24.79 \mathrm{Mg} \mathrm{km} \mathrm{ha}^{-1}$, no-tillage with traffic intensity of $49.59 \mathrm{Mg} \mathrm{km} \mathrm{ha}^{-1}$, minimum tillage and minimum tillage in compacted soil with $24.67 \mathrm{Mg} \mathrm{km} \mathrm{ha}^{-1}$. Data were collected for: total porosity; bulk density; penetration resistance; and for horizontal, vertical and draught forces demanded from the fertilizer planters. The subsoiling of minimum tillage used as an isolated technique did not reduce the compaction effects by a traffic intensity of $24,67 \mathrm{Mg} \mathrm{km} \mathrm{ha}^{-1}$. The traffic changes the soil structure but not the draught requirement. The changes in its intensity from 24.79 to $49.59 \mathrm{Mg} \mathrm{km} \mathrm{ha}{ }^{-1}$ does not further affect in the evaluated properties.
\end{abstract}

Index terms: compaction, minimum tillage, soil density, soil structure, no-tillage, subsoiling.

\section{Introdução}

O manejo incorreto do tráfego de tratores e máquinas agrícolas, principalmente quando o teor de água está acima do ponto de friabilidade e próximo ao limite plástico, têm ocasionado problemas de compactação em sistemas motomecanizados (Håkansson, 2005). Esse processo ocorre quando as pressões aplicadas ao solo são maiores do que a capacidade de suporte de carga (Alakuku et al., 2003).

A compactação promove alterações na relação massa-volume do solo, o que gera impactos negativos em suas propriedades físicas, como redução na infiltração e no armazenamento de água (Soane \& Ouwerkerk, 1995; Brandão et al. 2006), redução da capacidade de aeração e da permeabilidade ao ar e água (Reichert et al., 2007) e impedimento mecânico ao crescimento do sistema radicular (Streck et al., 2004). Efeitos como a redução do desempenho das máquinas e implementos, principalmente em razão do aumento na demanda de tração, também são observados em solos compactados (Rosa et al., 2008, Conte et al., 2009, Mentges et al., 2010). Oliveira et al. (2003) demonstram que a compactação afetou

Pesq. agropec. bras., Brasília, v.47, n.1, p.118-126, jan. 2012 
o desempenho de uma semeadora em um Argissolo Vermelho-Amarelo e um Latossolo Vermelho-Amarelo argiloso, com incrementos no consumo de combustível e na patinagem e, por consequência, na exigência de potência do trator. A profundidade do sulco de semeadura também é reduzida com o aumento da compactação do solo (Casão Júnior et al., 1998).

Segundo Mentges et al. (2010), alterações estruturais em um Argissolo Vermelho-Amarelo francoarenoso sob plantio direto (aumento na densidade e redução da porosidade total e macroporosidade), causadas pelo tráfego de uma pá carregadora de $10 \mathrm{Mg}$ (intensidade de tráfego de 24,67 $\mathrm{Mg} \mathrm{km} \mathrm{ha}^{-1}$ ), elevaram em 21,64\% a demanda média de tração de uma haste escarificadora, quando comparada à área sem tráfego adicional. Em um Argissolo Vermelho francoargiloso, Conte et al. (2009) atribuíram o aumento nos esforços de tração demandada pela haste sulcadora de semeadora ao tráfego, por quatro anos, de um trator de $3,52 \mathrm{Mg}$. Contudo, estudos sobre os efeitos da intensidade do tráfego são escassos.

$\mathrm{O}$ uso de escarificadores ou subsoladores pode atenuar os efeitos da compactação do solo sobre a demanda de tração, conforme salientam Håkansson (2005), Raper (2005) e Rosa et al. (2008). Contudo, seus efeitos têm duração dependente do manejo dado ao solo (Tormena et al., 2002; Raper, 2005; Botta et al., 2006). Furlani et al. (2005) não encontraram diferença no esforço de tração de uma semeadora com haste sulcadora, em Latossolo Vermelho sob sistemas de preparo do solo convencional, plantio direto e cultivo mínimo. Similarmente, Mahl et al. (2004) não observaram diferenças significativas em Nitossolo sob plantio direto, sem escarificação e escarificado 18 meses antes do plantio. Segundo Tormena et al. (2002), Raper (2005), Botta et al. (2006) e Rosa et al. (2008), o tempo de duração do efeito da escarificação no solo de textura argilosa está entre dois e quatro anos.

No entanto, o estudo da utilização do cultivo mínimo como estratégia de atenuar os efeitos nocivos da compactação no solo, que analisem principalmente as propriedades físicas e a demanda de tração, ainda são escassos.

O objetivo deste trabalho foi avaliar o efeito da intensidade de tráfego e do sistema de manejo na demanda de tração de uma haste sulcadora de adubo e nas propriedades físicas de um Argissolo Vermelho-Amarelo.

\section{Material e Métodos}

As coletas foram realizadas no segundo semestre de 2006, na área experimental do Departamento de Solos da Universidade Federal de Santa Maria (29 41' $00^{\prime \prime S}$ e $53^{\circ} 48^{\prime} 00^{\prime \prime} \mathrm{W}$ e altitude de $95 \mathrm{~m}$ ). O clima da região é do tipo Cfa, conforme a classificação de Köppen. O solo é classificado como Argissolo Vermelho-Amarelo distrófico arênico (Santos et al., 2006), de textura francoargiloarenosa. Maiores detalhes da caracterização granulométrica e química constam na Tabela 1. A área foi manejada com plantio direto por mais de 13 anos, com produção de milho/aveia e soja/azevém, respectivamente, em 2005 e 2006.

Empregou-se o delineamento experimental de blocos ao acaso, com cinco tratamentos e três repetições, dispostos em parcelas de 6x8 m. Os tratamentos foram: semeadura direta com tráfego natural (SDtn); semeadura direta com intensidade de tráfego adicional de 24,79 $\mathrm{Mg} \mathrm{km} \mathrm{ha}^{-1}$ (SDta1); semeadura direta com intensidade de tráfego adicional de 49,59 $\mathrm{Mg} \mathrm{km} \mathrm{ha}^{-1}$ (SDta2); cultivo mínimo (CM); e cultivo mínimo em solo compactado com intensidade de $24,67 \mathrm{Mg} \mathrm{km}$ ha $^{-1}(\mathrm{CMc})$ (pressão de contato de 260,7 kPa). Antes das avaliações, a área havia sido submetida ao tráfego em operações de semeadura, pulverização e colheita; o histórico, contudo, não é preciso quanto à intensidade empregada. A descrição do cálculo da intensidade de tráfego consta em Rosa (2009).

O tráfego aplicado aos tratamentos SDta1 e SDta2 foi realizado com um conjunto trator $(2,9 \mathrm{Mg})$ de 75 cv $(55,5 \mathrm{~kW})$ de potência nominal no motor e um pulverizador hidráulico montado de $600 \mathrm{~L}(0,88 \mathrm{Mg})$, o que resultou em pressão de contato do pneu traseiro com o solo de $102,95 \mathrm{kPa}$. O trator estava equipado com pneus dianteiros modelo 7.5-16 (Goodyear, São Paulo, SP, Brasil), calibrados com pressão de inflação de $32 \mathrm{lbf} \mathrm{pol}^{-2}$, e pneus traseiros modelo 18.4-30 R2

Tabela 1. Composição granulométrica e atributos químicos do Argissolo Vermelho-Amarelo do experimento ${ }^{(1)}$.

\begin{tabular}{lcccccccc}
\hline $\begin{array}{l}\text { Camada } \\
(\mathrm{m})\end{array}$ & \multicolumn{2}{c}{ Areia } & $\begin{array}{c}\text { Silte } \\
\left(\mathrm{g} \mathrm{kg}^{-1}\right)\end{array}$ & ------ & & $\begin{array}{c}\mathrm{M} g \\
\left(\mathrm{~g} \mathrm{~kg}^{-1}\right)\end{array}$ & $\begin{array}{c}\mathrm{m} \\
--\end{array}(\%)$ & $\begin{array}{c}\mathrm{CTCe} \\
\left(\mathrm{cmol}_{\mathrm{c}} \mathrm{dm}^{-3}\right)\end{array}$ \\
\hline $0,0-0,1$ & 600 & 212 & 188 & 5,3 & 25 & 2 & 71 & 5,4 \\
$0,1-0,2$ & 566 & 215 & 219 & 5,0 & 15 & 14 & 69 & 5,1 \\
$0,2-0,3$ & 558 & 232 & 210 & 5,1 & 12 & 19 & 60 & 4,8 \\
$0,3-0,4$ & 566 & 236 & 198 & 5,0 & 12 & 31 & 53 & 4,2 \\
\hline
\end{tabular}

${ }^{(1)} \mathrm{MO}$, matéria orgânica; m, saturação por alumínio; V, saturação por bases; CTCe, capacidade de troca catiônica efetiva. ${ }^{(2)} \mathrm{pH}$ em água 1:1. 
(Pirelli, Campinas, SP, Brasil), calibrados com 15 lbf $\mathrm{pol}^{-2}$. A intensidade de tráfego dos tratamentos SDta1 e SDta2 foram obtidas, respectivamente, por quatro e oito passadas do conjunto acima descrito.

Para o tratamento $\mathrm{CMc}$, antes da subsolagem, o solo foi compactado pelo tráfego de uma pá carregadora de aproximadamente $10 \mathrm{Mg}$, tendo sido executadas duas passadas. A pá carregadora 75III (Clarck-Michigan, Pederneiras, SP, Brasil), com massa total de 7,74 Mg, foi carregada com solo (na concha), para aumentar a massa no eixo frontal da máquina e garantir massa total de $10 \mathrm{Mg}$. Os pneus, modelo PN $14 \mathrm{G} 2 / \mathrm{L} 2$, 13-24 10PR (Pirelli, Campinas, SP, Brasil), tinham as garradeiras desgastadas pelo uso, o que evitou o cisalhamento superficial. A pressão de inflação destes pneus foi de $202,46 \mathrm{kPa}$, o que gerou uma pressão de contato de $260,7 \mathrm{kPa}$.

A compactação das áreas do experimento foi realizada de modo que os pneus comprimissem áreas paralelas entre si, com as passadas sobrepostas às anteriores, para que toda a área fosse igualmente trafegada; e executadas no sentido longitudinal da parcela, ou seja, no mesmo sentido da semeadura. No momento da compactação com a pá carregadora, a área encontrava-se coberta com 1,43 $\mathrm{Mg} \mathrm{ha}^{-1}$ de matéria seca de azevém (Lolium multiflorum Lam.) e a consistência do solo encontrava-se na condição friável, nos tratamentos SDta1 e SDta2, e seco, para o $\mathrm{CMc}$, com teores de água de $0,18,0,18$ e $0,15 \mathrm{~kg} \mathrm{~kg}^{-1}$, respectivamente, na camada $0,0-0,3 \mathrm{~m}$.

A subsolagem dos tratamentos $\mathrm{CM}$ e $\mathrm{CMc}$ foi realizada à profundidade média de $0,25 \mathrm{~m}$, com um subsolador montado e tracionado à velocidade de $4,3 \mathrm{~km}$ por hora. O implemento tem as seguintes especificações: estrutura porta-ferramenta em formato trapezoidal, com rodas niveladoras de profundidade acopladas ao chassi e uma haste em curva $\left(45^{\circ}\right)$ com ponteira estreita de $0,08 \mathrm{~m}$ de largura e ângulo de ataque de $20^{\circ}$. No momento dessa operação, a área encontrava-se coberta com azevém, e o teor de água do solo era de $0,295 \mathrm{~m}^{3} \mathrm{~m}^{-3}$. O implemento foi tracionado por um trator de $65 \mathrm{cv}(48,1 \mathrm{~kW}) \mathrm{de}$ potência no motor, sem tração dianteira auxiliar (TDA) e com peso de 2,665 Mg. Os pneus dianteiros, modelo 7.5-16 (Goodyear, São Paulo, SP, Brasil) estavam calibrados com pressão de inflação $165,47 \mathrm{kPa}$ e os pneus traseiros, modelo 18.4-30 (Pirelli, Campinas, SP, Brasil) calibrados com 55,16 kPa.
A semeadura foi realizada com uma semeadora de quatro linhas, espaçadas em $0,6 \mathrm{~m}$, com sulcador de adubo tipo guilhotina e sulcador de semente tipo disco defasado, tracionado pelo mesmo trator empregado na compactação do SDta1 e SDta2. As avaliações foram realizadas cinco meses após a compactação do solo sob semeadura direta, no período de pleno florescimento do milho.

Para analisar a influência da intensidade de trafego na máquina, foi mensurada a demanda de esforços exigida pela haste sulcadora de adubo de uma semeadora. Para tal, foram feitas passadas com haste sulcadora de adubo tipo facão em todos os tratamentos em estudo e mensurados o esforço horizontal $\left(\mathrm{F}_{\mathrm{H}}\right)$, esforço vertical $\left(\mathrm{F}_{\mathrm{V}}\right)$ e o momento associado $\left(\mathrm{M}_{\mathrm{O}}\right)$, e calculado o esforço de tração $\left(\mathrm{F}_{\mathrm{T}}\right)$. Os dados de esforços foram obtidos com auxílio de um anel octogonal estendido, ligado a um módulo de aquisição de dados pertencentes à Embrapa Trigo. $\mathrm{O}$ anel foi instalado entre a haste sulcadora e a barra porta-ferramenta, e foi configurado para a taxa de aquisição de 20 dados por segundo $(20 \mathrm{~Hz})$.

Amostras de solo com estrutura preservada foram coletadas nas camadas $0,00-0,05,0,05-0,15,0,15-0,25$ e $0,25-0,35 \mathrm{~m}$ para a determinação de macroporosidade (Ma), microporosidade (Mi), porosidade total (Pt) e densidade do solo (Ds) (Claessen,1997). Foram coletadas, também, informações sobre a resistência do solo à penetração (RP), medida até $0,40 \mathrm{~m}$ de profundidade, tendo-se realizado três leituras ao longo da parcela. Para tal, fez-se uso de um penetrômetro digital, modelo CP20 Ultrasonic (Rimik, Toowoomba, Austrália), equipado com ponta cônica (ângulo de penetração de $30^{\circ}$ ) e armazenamento eletrônico de dados. A aquisição dos dados foi realizada a cada $0,015 \mathrm{~m}$ de profundidade. No momento dessa determinação, o solo encontrava-se com teor de água entre 0,12 e $0,15 \mathrm{~kg} \mathrm{~kg}^{-1}$ ao longo da profundidade avaliada. Convém ressaltar que as amostragens foram realizadas na linha de cultivo do milho, a fim de avaliar a que tipo de condições físicas do solo o sistema radicular da cultura estava submetido.

Em razão da quantidade de dados coletados, optou-se por avaliar a demanda de esforços pela comparação de médias, por meio do teste t de Student, a 5\% de probabilidade de erro, pois este leva em consideração a variação de cada tratamento. Para as demais variáveis avaliadas, foi realizada a comparação entre médias pelo teste de Tukey, a 5\% de probabilidade. Ambas 
as análises foram realizadas com uso do programa estatístico SAS (SAS Institute, 1990).

\section{Resultados e Discussão}

Os tratamentos apresentaram baixos valores de macroporosidade (Ma) ao longo do perfil; em alguns casos, até mesmo inferior aos $10 \%$ considerados como críticos ao adequado desenvolvimento das plantas (Reichert et al., 2007) (Tabela 2). Na camada superficial $(0,00-0,05 \mathrm{~m})$, diferenças significativas ocorreram entre o tratamento que teve a maior intensidade de

Tabela 2. Macroporosidade (Ma), microporosidade (Mi), porosidade total $(\mathrm{Pt})$, densidade do solo (Ds) e resistência à penetração (RP) médios observados em Argissolo Vermelho-Amarelo submetido a diferentes manejos ${ }^{(1)}$.

\begin{tabular}{|c|c|c|c|c|c|}
\hline Tratamento $^{(2)}$ & Ma & $\begin{array}{c}\mathrm{Mi} \\
-(\%)---\cdot\end{array}$ & Pt & $\begin{array}{c}\text { Ds } \\
\left(\mathrm{Mg} \mathrm{m}^{-3}\right)\end{array}$ & $\begin{array}{c}\mathrm{RP} \\
(\mathrm{MPa})\end{array}$ \\
\hline & \multicolumn{5}{|c|}{ Camada $0-0,05 \mathrm{~m}$} \\
\hline SDtn & $14,4 \mathrm{a}$ & $30,1 \mathrm{ab}$ & $44,5 \mathrm{a}$ & $1,40 \mathrm{a}$ & $0,52 b$ \\
\hline SDta1 & $10,8 \mathrm{ab}$ & $28,5 b$ & $39,3 \mathrm{a}$ & $1,53 \mathrm{a}$ & $1,22 \mathrm{a}$ \\
\hline SDta2 & $9,3 b$ & $30,8 \mathrm{ab}$ & $40,0 \mathrm{a}$ & $1,51 \mathrm{a}$ & $0,83 \mathrm{ab}$ \\
\hline $\mathrm{CM}$ & $13,2 \mathrm{ab}$ & $32,2 \mathrm{a}$ & $45,3 \mathrm{a}$ & $1,38 \mathrm{a}$ & $0,76 \mathrm{ab}$ \\
\hline $\mathrm{CMc}$ & $15,2 \mathrm{a}$ & $29,6 \mathrm{ab}$ & $44,8 \mathrm{a}$ & $1,39 \mathrm{a}$ & $0,77 \mathrm{ab}$ \\
\hline \multirow[t]{2}{*}{ CV (\%) } & 22,4 & 5,2 & 7,0 & 5,16 & 36,19 \\
\hline & \multicolumn{5}{|c|}{ Camada $0,05-0,15 \mathrm{~m}$} \\
\hline SDtn & $6,2 \mathrm{a}$ & $29,1 \mathrm{a}$ & $35,3 \mathrm{a}$ & $1,63 \mathrm{a}$ & $1,18 \mathrm{a}$ \\
\hline SDta1 & $6,1 \mathrm{a}$ & $30,5 \mathrm{a}$ & $36,6 \mathrm{a}$ & $1,60 \mathrm{a}$ & $1,79 \mathrm{a}$ \\
\hline SDta2 & $4,9 \mathrm{a}$ & $29,5 \mathrm{a}$ & $34,4 \mathrm{a}$ & $1,65 \mathrm{a}$ & $2,20 \mathrm{a}$ \\
\hline $\mathrm{CM}$ & $8,5 \mathrm{a}$ & $29,6 \mathrm{a}$ & $38,1 \mathrm{a}$ & $1,56 \mathrm{a}$ & $1,87 \mathrm{a}$ \\
\hline $\mathrm{CMc}$ & $6,5 \mathrm{a}$ & $28,6 \mathrm{a}$ & $35,1 \mathrm{a}$ & $1,64 \mathrm{a}$ & $2,17 \mathrm{a}$ \\
\hline \multirow[t]{2}{*}{ CV (\%) } & 41,2 & 3,9 & 6,1 & 3,38 & 37,21 \\
\hline & \multicolumn{5}{|c|}{ Camada $0,15-0,25 \mathrm{~m}$} \\
\hline SDtn & $7,5 \mathrm{ab}$ & $28,9 \mathrm{a}$ & $36,4 \mathrm{ab}$ & $1,63 \mathrm{ab}$ & $1,70 \mathrm{c}$ \\
\hline SDta1 & $11,0 \mathrm{a}$ & $29,2 \mathrm{a}$ & $40,1 \mathrm{ab}$ & $1,54 \mathrm{ab}$ & $1,85 \mathrm{bc}$ \\
\hline SDta2 & $10,1 \mathrm{ab}$ & $30,4 a$ & $40,6 \mathrm{a}$ & $1,52 \mathrm{~b}$ & $2,24 \mathrm{abc}$ \\
\hline $\mathrm{CM}$ & $9,5 \mathrm{ab}$ & $29,4 \mathrm{a}$ & $38,9 \mathrm{ab}$ & $1,57 \mathrm{ab}$ & $2,67 \mathrm{a}$ \\
\hline $\mathrm{CMc}$ & $6,4 b$ & $28,7 \mathrm{a}$ & $35,1 \mathrm{~b}$ & $1,67 \mathrm{a}$ & $2,82 \mathrm{ab}$ \\
\hline \multirow[t]{2}{*}{ CV (\%) } & 20,4 & 4,7 & 6,1 & 3,90 & 25,44 \\
\hline & \multicolumn{5}{|c|}{ Camada $0,25-0,35 \mathrm{~m}$} \\
\hline SDtn & $7,4 \mathrm{~b}$ & $29,6 \mathrm{a}$ & $36,9 b$ & $1,61 \mathrm{ab}$ & $2,19 a$ \\
\hline SDta1 & $9,5 \mathrm{ab}$ & $29,7 \mathrm{a}$ & $39,2 \mathrm{ab}$ & $1,55 \mathrm{abc}$ & $1,86 \mathrm{a}$ \\
\hline SDta2 & $11,2 \mathrm{ab}$ & $30,6 a$ & $41,8 \mathrm{a}$ & $1,49 \mathrm{bc}$ & $1,69 \mathrm{a}$ \\
\hline CM & $12,1 \mathrm{a}$ & $29,7 \mathrm{a}$ & $41,9 a$ & $1,48 \mathrm{c}$ & $2,30 \mathrm{a}$ \\
\hline $\mathrm{CMc}$ & $7,2 \mathrm{~b}$ & $29,2 \mathrm{a}$ & $36,3 b$ & $1,63 \mathrm{a}$ & $2,30 \mathrm{a}$ \\
\hline CV (\%) & 21,5 & 3,4 & 5,4 & 3,44 & 20,20 \\
\hline
\end{tabular}

${ }^{(1)}$ Médias seguidas de letras iguais, nas colunas, não diferiram entre si pelo teste de Tukey, a $5 \%$ de probabilidade. ${ }^{(2)} \mathrm{SDtn}$, semeadura direta por 13 anos com tráfego natural; SDta1, semeadura direta com tráfego adicional de 24,79 $\mathrm{Mg} \mathrm{km} \mathrm{ha}^{-1}$; SDta2, semeadura direta com tráfego adicional de 49,59 $\mathrm{Mg} \mathrm{km} \mathrm{ha}^{-1} ; \mathrm{CM}$, cultivo mínimo; CMc, cultivo mínimo em solo compactado por intensidade de tráfego de $24,67 \mathrm{Mg} \mathrm{km} \mathrm{ha}^{-1}$. tráfego (SDta2) e os tratamentos com cultivo mínimo em solo compactado $(\mathrm{CMc})$ e sem tráfego adicional (SDtn), e esses não diferiram dos demais. A camada de $0,05-0,15 \mathrm{~m}$ apresentou os menores valores de Ma, combinados com maiores valores de Ds, o que indica a ocorrência de camada compactada. Resultados semelhantes foram obtidos por Abreu et al. (2004) e Streck et al. (2004), que afirmam ser essa a camada de concentração das tensões geradas pelo tráfego de máquinas agrícolas em solos cultivados sob o sistema de semeadura direta.

O tráfego também afetou a microporosidade e a resistência do solo à penetração, na camada superficial (Tabela 2). O tratamento CM diferiu do SDta1 quanto à microporosidade, tendo apresentado os maiores valores, porém sem diferir dos demais tratamentos. Este comportamento era esperado, em razão da mobilização ocorrida na rugosidade superficial do solo com a subsolagem, pois a falta de disco de corte no implemento resulta no arraste da cobertura vegetal até um ponto em que a patinagem do trator aumenta e submete o solo a maior pressão. Tal fato, visualizado no momento da execução dessa operação, causou o aumento da compactação e, provavelmente, a ineficiência do subsolador.

A RP foi maior no tratamento SDta1, sem ter sido, no entanto, restritiva ao adequado desenvolvimento das plantas ( $<2 \mathrm{MPa}$ ) (Tormena et al, 2008). Maiores valores de RP foram encontrados nas camadas mais profundas, com consequência das alterações (aumento na Ds e redução da MA) geradas pelo tráfego, o que evidencia a influência deste até essas camadas.

Não foram encontradas diferenças significativas para a variável Ds, até a profundidade de $0,15 \mathrm{~m}$. A segunda camada, inclusive, não apresentou diferença para as demais variáveis avaliadas, o que indica um elevado estado de compactação em todos os tratamentos e que a subsolagem não foi eficiente na descompactação do solo.

Altos valores de Ds foram encontrados nos tratamentos CM e CMc, na camada de 0,15-0,25 m, o que corrobora a constatação anterior, que indicou que o aumento da patinagem durante a subsolagem resultou em aumento na compactação. Nos tratamentos SDta1 e SDta2, a maior Ds ao longo das camadas avaliadas ocorreu na profundidade de $0,05-0,15 \mathrm{~m}$. Similarmente a essa constatação, Kamimura (2008) observou, em um Argissolo Vermelho cultivado sob 
o sistema de semeadura direta, a ocorrência de maior Ds na camada $0,12-0,15 \mathrm{~m}$ e que os valores dessa não diferiram quando o solo foi trafegado por um trator agrícola ou por uma colhedora. Em experimentos com cultivo de feijão sob semeadura direta, Collares et al. (2006) constataram que a maior densidade ocorreu à profundidade de $0,12 \mathrm{~m}$ e que ela restringiu o desenvolvimento da cultura. No entanto, em solos arenosos, Czyz (2004) constatou maior densidade na camada $0,32-0,37 \mathrm{~m}$, sob intensidades de tráfego de zero e quatro passadas de um trator de $1,7 \mathrm{Mg}$ de peso no eixo traseiro. Valores similares aos de Czyz (2004) foram observados no presente estudo. Já Botta et al. (2004) encontraram uma camada mais densa na profundidade de $0,3-0,6 \mathrm{~m}$, em solo arenoso submetido a quatro, seis e oito passadas de trator.

As diferenças entre os resultados estão provavelmente associadas ao teor de água do solo no momento do tráfego, que pode contribuir para a maior transmissão das tensões em maiores profundidades. Håkansson (2005) salienta que, além do teor de água do solo, o grau de compactação é outro fator determinante para o aumento da compactação. Outro ponto-chave é a capacidade de suporte de carga do solo, expressa pela pressão de preconsolidação, em que pressões de tráfego maiores que ela ocasionam compactação ao solo.

Alteraçõesnacamada 0,15-0,25 mforamvisualizadas em todas as propriedades físicas analisadas, exceto pela microporosidade (Mi). Nessa camada, percebeu-se que a intensidade de tráfego de $24,67 \mathrm{Mg} \mathrm{km} \mathrm{ha}^{-1}$ gerou um grau de compactação que não foi reduzido pela subsolagem $(\mathrm{CMc})$, fato corroborado pela menor Pt do solo observada neste tratamento. Segundo Mantovani (1987), a porosidade se constitui no parâmetro de maior expressividade na avaliação do efeito da compactação no solo, pois fornece a informação direta da proporção de volume do solo disponível ao fluxo de ar e água.

Tomando-se como base o triângulo textural proposto por Reichert et al. (2007), o limite crítico de Ds de um solo de textura francoarenosa é de 1,7-1,8 $\mathrm{Mg} \mathrm{m}^{-3}$, valores bem superiores aos encontrados no presente estudo. Contudo, cuidados devem ser tomados, pois segundo Daddow \& Warrington (1983), a Ds de 1,65 $\mathrm{Mg} \mathrm{m}^{-3}$ já impõe restrições ao desenvolvimento radicular de plantas.

O aumento da intensidade de tráfego de 24,79 para 49,59 $\mathrm{Mg} \mathrm{km} \mathrm{ha}^{-1}$ não foi suficiente para gerar alteração significativa em Ma, Mi, Pt e Ds. Esse resultado pode ser atribuído à granulometria do solo. Em solo francosiltoso, Jorajuria \& Draghi (2000) observaram efeito de intensidades de tráfego, similares às do presente estudo, sobre Ds. Esse resultado está associado ao fato de que a transmissão das tensões geradas pelo tráfego de máquinas agrícolas é mais expressiva em solo argiloso e siltoso, e à maior adesão desses solos, propriedades estas que influenciam o grau de compactação (Larson et al., 1980; Guérif, 1984).

$\mathrm{Na}$ última camada, que não teve ação direta do subsolador, a presença de compactação ainda foi visualizada em $\mathrm{CMc}$, pois este tratamento apresentou macroporosidade de $7,2 \%$, que não diferiu do solo com semeadura direta com e sem tráfego. Além disso, a resistência à penetração foi maior nestes tratamentos, o que mostra que a camada arável do solo deve ser trabalhada para melhorar suas propriedades físicas.

A resistência mecânica do solo à penetração é considerada como o parâmetro do solo mais sensível na detecção do efeito da compactação (Jorajuria \& Draghi, 2000, Botta et al., 2002, Streck et al., 2004 e Collares et al., 2006). Assim, pode-se utilizar esse parâmetro no planejamento do tráfego de máquinas agrícolas, para evitar a compressão excessiva ao solo, desde que ela seja analisada em conjunto com os dados de teor de umidade do solo. O efeito do tráfego pode ser visualizado no aumento da RP em CMc, o que confirma que a compactação excessiva não é resolvida apenas com subsolador.

O grau de compactação aumentou gradualmente a demanda de esforços (horizontal, vertical e de tração) exigida na haste sulcadora (Figura 1 e 2). $\mathrm{O}$ aumento da intensidade de 24,79 para 49,59 $\mathrm{Mg} \mathrm{km} \mathrm{ha}^{-1}$ não provocou alterações nos esforços, além dos gerados na primeira intensidade de tráfego. Efeito similar foi observado por Bonini et al. (2008), em Latossolo Vermelho compactado com intensidades de tráfego de zero a cinco passadas de um rolo compactador. Isso está relacionado às alterações impostas pelo tráfego de $24,79 \mathrm{Mg} \mathrm{km} \mathrm{ha}^{-1}$, que já havia provocado compactação. Assim, a estrutura aumentou sua capacidade de suporte. Esse aumento foi acompanhado pela maior resistência do solo (Tabela 2). Não houve diferença entre os solos manejados com semeadura direta; as diferenças ocorreram no solo manejado com cultivo mínimo, em que o $\mathrm{CMc}$ apresentou a maior demanda, o que corrobora a constatação anterior de elevada compactação do solo. 

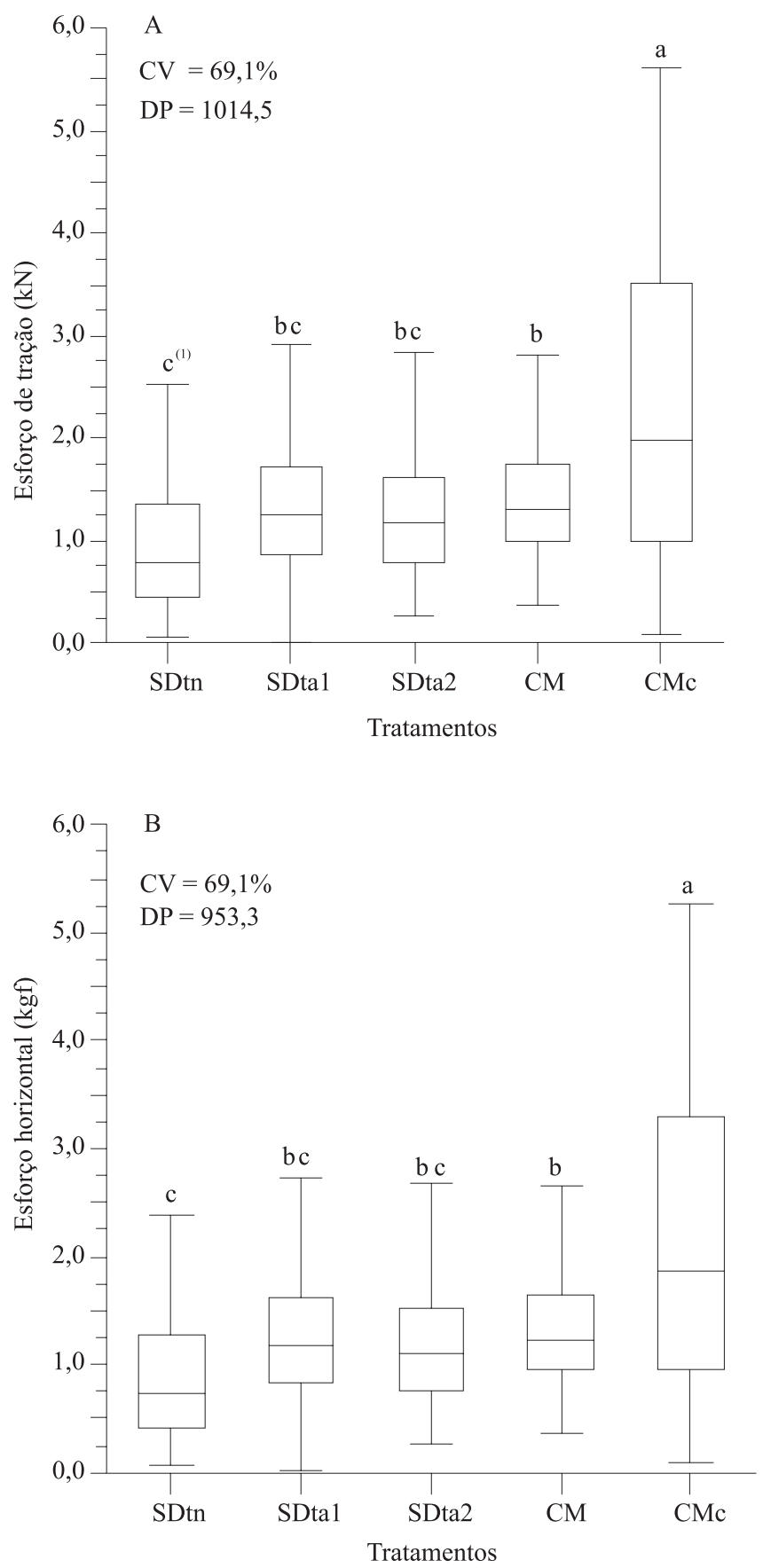

Figura 1. Percentis do esforço de tração (A) e do esforço horizontal (B) demandados à haste escarificadora em Argissolo Vermelho-Amarelo submetido a diferentes manejos. ${ }^{(1)}$ Médias seguidas de letras iguais não diferem entre si pelo teste de Tukey, a 5\% de probabilidade. SDtn, semeadura direta por 13 anos com tráfego natural; SDta1, semeadura direta com tráfego adicional de 24,79 $\mathrm{Mg} \mathrm{km} \mathrm{ha}^{-1}$; SDta2, semeadura direta com tráfego adicional de 49,59 Mg $\mathrm{km} \mathrm{ha}^{-1}$; CM, cultivo mínimo; CMc, cultivo mínimo em solo compactado por intensidade de tráfego de 24,67 $\mathrm{Mg} \mathrm{km} \mathrm{ha}^{-1}$. $\mathrm{CV}$, coeficiente de variação; DP, desvio padrão.
Os sistemas de manejo apresentaram variações diferenciadas, tanto no esforço horizontal e vertical, como no de tração. A compactação nos tratamentos sob cultivo mínimo gerou maior resistência à mobilização do solo pelo subsolador. Isso também foi observado em um Latossolo argiloso por Rosa et al. (2008), em que a menor demanda de esforço horizontal foi apresentada pelo solo escarificado seis meses antes do plantio. Porém, em Nitossolo Vermelho, Mahl et al. (2004) não encontraram variação na demanda de esforço de tração entre solo submetido ao plantio direto e ao cultivo mínimo 18 meses antes do plantio. Efeito similar ao observado por Mahl et al. (2004) foi encontrado por Furlani et al. (2005), em um Latossolo Vermelho-Escuro, em que o maior consumo de combustível foi observado no solo sob cultivo mínimo. A alta demanda de esforços no solo sob cultivo mínimo compactado, em conjunto com a maior resistência à penetração e menor porosidade do solo, confirma o

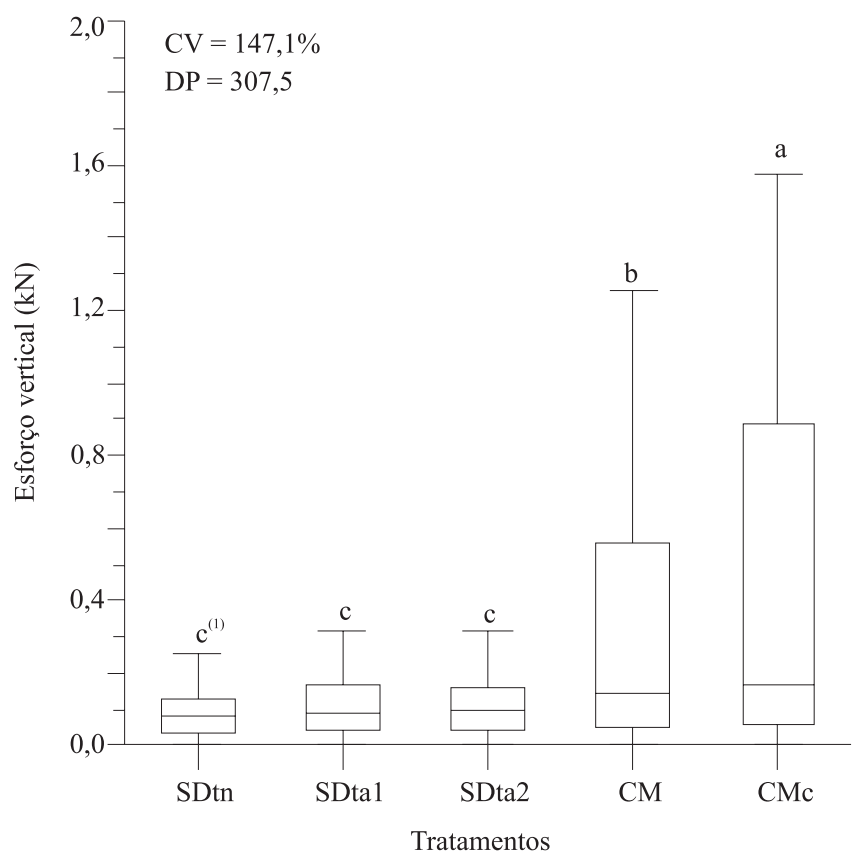

Figura 2. Percentis dos esforços verticais demandados à haste escarificadora em Argissolo Vermelho-Amarelo submetido a diferentes manejos. Médias seguidas de letras iguais não diferem entre si pelo teste de Tukey, a 5\% de probabilidade. SDtn, semeadura direta por 13 anos com tráfego natural; SDta1, semeadura direta com tráfego adicional de 24,79 Mg $\mathrm{km} \mathrm{ha}^{-1}$; SDta2, semeadura direta com tráfego adicional de 49,59 Mg km ha-1; CM, cultivo mínimo; CMc, cultivo mínimo em solo compactado por intensidade de tráfego de 24,67 Mg $\mathrm{km} \mathrm{ha}^{-1}$. CV, coeficiente de variação; DP, desvio padrão. 
elevado grau de compactação deste solo e a ineficiência do escarificador, como técnica isolada, na redução desses efeitos. Tomando-se como referência os valores de demanda de tração preconizados pela American Society of Agricultural Engineers (1996), o solo sob CMc apresentou valores bem mais elevados.

Algumas práticas podem ser empregadas para a minimização e controle da compactação, como estímulo à atividade biológica do solo (quando o nível de compactação não é excessivo), controle de tráfego (Botta et al., 2004), adequada pressão de insuflagem (Håkansson, 2005), tráfego em condições de friabilidade do solo, uso de mecanismos rompedores de solo com mínima perturbação da estrutura (Spoor et al., 2003) e uso de haste sulcadora na semeadura. A escolha da ação dependerá do nível de compactação do solo. A descompactação deve ter a meta de fissurar o solo, e não de rotacioná-lo, e o emprego de escarificadores contribui para esse efeito (Spoor et al., 2003). Esse autor ressalta que, independentemente da prática utilizada para descompactação, deve-se considerar a não alteração da capacidade de suporte de carga do solo. Dessa forma não deve-se realizar tráfego após a escarificação, pelo fato de o solo estar em fase de reestruturação.

$\mathrm{Na}$ comparação da variação dos quartis $25-75 \%$ de esforço horizontal, nos tratamentos sob semeadura direta, verificou-se que SDtn variou de 0,53 a $1,16 \mathrm{kN}$, SDta1 de 0,62 a 1,43 kN, e SDta2 de 0,55 a 1,40 kN. Embora não tenha havido diferenças significativas, cuidados devem ser tomados com a intensidade de tráfego, pois percebe-se que houve aumento da demanda quando o solo foi trafegado. Porém, o tratamento SDta2 não provocou expressivas alterações em comparação ao tratamento SDta1.

O esforço vertical máximo foi encontrado no tratamento $\mathrm{CMc}$, que apresentou valor maior do que a média do esforço horizontal da maioria dos tratamentos em estudo. Isso pode acarretar maior desuniformidade da profundidade de trabalho e gerar maior consumo de combustível. Em Latossolo Vermelho sob plantio direto e cultivo mínimo com diferentes tempos de implantação, Rosa et al. (2008) observaram, no máximo, $5,5 \mathrm{kN}$ de esforço vertical, valor bem abaixo do obtido no presente estudo. Contudo, a demanda de esforço horizontal chegou a $3,17 \mathrm{kN}$, o que mostra que a ação do carregamento em solo arenoso é maior na compactação vertical.
A subsolagem elevou a resistência do solo, pois demandou a maior tração entre os tratamentos, o que confirma que não há mais efeito deste processo na demanda de esforços, e que o solo encontra-se em situações diferentes da condição inicial. Após quatro anos da realização da escarificação, Rosa et al. (2008) concluíram que o solo apresentava condições diferentes do solo sob plantio direto, o que se manifestou pela maior demanda de tração. Similarmente, Furlani et al. (2004) encontraram demanda de tração diferente entre o Nitossolo Vermelho escarificado do solo sob semeadura direta, em que a maior demanda foi exigida pelo solo escarificado. Esses autores observaram que a capacidade de campo efetiva no solo escarificado foi menor, em consequência da maior patinagem e demanda de tração. A elevação da demanda de tração no solo escarificado resulta em maior demanda energética. Conforme Casão Júnior et al. (1998), é comum o trator não ter reserva de torque suficiente para o serviço de semeadura.

A demanda de tração no solo compactado que sofreu subsolagem pode ser considerada elevada. Em um Nitossolo Vermelho escarificado, Furlani et al. (2004) encontraram $2,42 \mathrm{kN}$, enquanto que em um Latossolo Vermelho, Rosa et al. (2008) observaram valores de $2,3 \mathrm{kN}$. Ambos os solos eram argilosos.

\section{Conclusões}

1. A subsolagem do cultivo mínimo, utilizada como técnica isolada de descompactação de solos trafegados com intensidade de 24,67 $\mathrm{Mg} \mathrm{km} \mathrm{ha}^{-1}$, não gera redução da demanda de tração solicitada pela haste sulcadora da semeadora.

2. A intensidade de tráfego de $29,74 \mathrm{Mg} \mathrm{km} \mathrm{ha-1}$ afeta a estrutura do Argissolo Vermelho-Amarelo, sem causar alterações significativas na demanda de tração requerida pela haste sulcadora de semeadora.

3. O aumento na intensidade de tráfego para 49,59 Mg km ha-1 não ocasiona maiores alterações nas propriedades físicas e na demanda de esforços, além das proporcionadas pela primeira intensidade.

4. O tráfego em Argissolo Vermelho-Amarelo cultivado sob o sistema de semeadura direta causa a ocorrência de camada compactada entre as profundidades de 0,05 a $0,15 \mathrm{~m}$, com valores de macroporosidade abaixo de $10 \%$ e resistência à penetração de aproximadamente $2 \mathrm{MPa}$. 


\section{Agradecimentos}

À Embrapa Trigo pelo empréstimo do anel octogonal.

\section{Referências}

ABREU, S.L.; REICHERT, J.M.; REINERT, D.J. Escarificação mecânica e biológica para a redução da compactação em Argissolo franco-arenoso sob plantio direto. Revista Brasileira de Ciência do Solo, v.28, p.519-531, 2004.

ALAKUKU, L.; WEISSKOPF, P.; CHAMEN, W.C.T.; TIJINK, F.G.J.; VAN DER LINDEN, J.P.; PIRES, S.; SOMMER, C.; SPOOR, G. Prevention strategies for field traffic-induced subsoil compaction: A review. Part 1. Mechine/soil interactions. Soil and Tillage Research, v.73, p.145-160, 2003.

AMERICAN SOCIETY OF AGRICULTURAL ENGINEERS. Terminology for soil- engaging components for conservation tillage planters, drills, and seeders. In: ASAE. Asae Standards 1996: standards engineering practices data. St. Joseph: ASAE, 1996. p.309-314.

BONINI, A.K.; GABRIEL FILHO, A.; SECCO, D.; SOUZA, R.F. de; TAVARES, C. Atributos físicos e requerimento de potência de uma semeadora-adubadora em um Latossolo sob estados de compactação. Engenharia Agrícola, v.28, p.136-144, 2008.

BOTTA, G.F.; JORAJURIA, D.; BALBUENA, R.; RESSIA, M.; FERRERO, C.; ROSATTO, H.; TOURN, M. Deep tillage and traffic effects on subsoil compaction and sunflower (Helianthus annus L.) yields. Soil and Tillage Research, v.91, p.164-172, 2006.

BOTTA, G.F.; JORAJURIA, D.; BALBUENA, R.; ROSATTO, $\mathrm{H}$. Mechanical and cropping behavior of direct drilled soil under different traffic intensities: effect on soybean (Glycine max L.) yields. Soil and Tillage Research, v.78, p.53-58, 2004.

BOTTA, G.F.; JORAJURIA, D.; DRAGHI, L.M. Influence of the axle load, tire size and configuration on the compaction of a freshly tilled clayey soil. Journal of Terramechanics, v.39, p.47-54, 2002.

BRANDÃO, V. dos S.; CECÍLIO, R.A.; PRUSKI, F.F.; SILVA, D.D. da. Infiltração da água no solo. 3.ed. Viçosa: UFV, 2006. 120p.

CASÃO JÚNIOR, R.; ARAÚJO, A.G. de; RALISCH, R.; SILVA, A.L. da; LADEIRA, A. de S.; SILVA, J.C. da; MACHADO, P.; ROSSETO, R. Avaliação do desempenho da semeadora-adubadora Magnum 2850 em plantio direto no basalto paranaense. Londrina: IAPAR, 1998. 47p. (IAPAR. Circular, 105).

CLAESSEN, M.E.C. (Org.). Manual de métodos de análise de solo. 2.ed. rev. atual. Rio de Janeiro: Embrapa-CNPS, 1997. 212p. (Embrapa-CNPS. Documentos, 1).

COLLARES, G.L.; REINERT, D.J.; REICHERT, J.M.; KAISER, D.R. Qualidade física do solo na produtividade da cultura do feijoeiro num Argissolo. Pesquisa Agropecuária Brasileira, v.41, p.1663-1674, 2006.

CONTE, O.; LEVIEN, R.; TREIN, C.R.; XAVIER, A.A.P.; DEBIASI, H. Demanda de tração, mobilização do solo na linha de semeadura e rendimento da soja, em plantio direto. Pesquisa Agropecuária Brasileira, V.44, P.1254-1261, 2009.

CZYZ, E.A. Effects of traffic on soil aeration, bulk density and growth of spring barley. Soil and Tillage Research, v.79, p.153-166, 2004.

DADDOW, R.L.; WARRINGTON, G.E. Growth-limiting soil bulk densities as influenced by soil texture. Fort Collins: Watershed Systems Development Group, 1983. 203p. (WSDG REPORT, TN-00005).

FURLANI, C.E.A.; GAMERO, C.A.; LEVIEN, R.; LOPES, A.; SILVA, R.P. da. Desempenho operacional de uma semeadora-adubadora de precisão, em função do preparo do solo e do manejo da cobertura de inverno. Engenharia Agrícola, v.24, p.388-395, 2004.

FURLANI, C.E.A.; LOPES, A.; SILVA, R.P. da. Avaliação de semeadora-adubadora de precisão trabalhando em três sistemas de preparo do solo. Engenharia Agrícola, v.25, p.458-464, 2005.

GUÉRIF, J. The influence of water-content gradient and structure anisotropy on soil compressibility. Journal of Agricultural Engineering Research, v.29, p.367-374, 1984.

HÅKANSSON, I. Machinery-induced compaction of arable soils: incidence, consequences, counter-measures. Uppsala: Faculty of Natural Resources, 2005. 153p.

JORAJURIA, C.D.; DRAGHI, L. Sobrecompactación del suelo agrícola parte I: influencia diferencial del peso y del número de pasadas. Revista Brasileira de Engenharia Agrícola e Ambiental, v.4, p.445-452, 2000.

KAMIMURA, K.M. Parâmetros de solo, máquina e planta em função de doses de resíduos vegetais e profundidades de deposição de fertilizantes em semeadura direta. 2008. 129p. Dissertação (Mestrado) - Universidade Federal do Rio Grande do Sul, Porto Alegre.

LARSON, W.E.; GUPTA, S.C.; USECHE, R.A. Compression of agricultural soils from eight soil orders. Soil Science Society of American Journal, v.44, p.450-457, 1980.

MAHL, D.; GAMERO, C.A.; BENEZ, S.H.; FURLANI, C.E.A.; SILVA, A.R.B. Demanda energética e eficiência da distribuição de sementes de milho sob variação de velocidade e condição de solo. Engenharia Agrícola, v.24, p.150-157, 2004.

MANTOVANI, E.C.Compactação do solo. InformeAgropecuário, V.13, p.52-55, 1987.

MENTGES, M.I.; REICHERT, J.M.; ROSA, D.P.; VIEIRA, D.A.; ROSA, V.T.; REINERT, D.J. Propriedades físico-hídricas do solo e demanda energética de haste escarificadora em Argissolo compactado. Pesquisa Agropecuária Brasileira, v.45, p.315-321, 2010 .

OLIVEIRA, G.C. de; DIAS JUNIOR, M. de S.; RESCK, D.V.S.; CURI, N. Alterações estruturais e comportamento compressivo de um Latossolo Vermelho distrófico argiloso sob diferentes sistemas de uso e manejo. Pesquisa Agropecuária Brasileira, v.38, p.291-299, 2003.

RAPER, R.L. Agricultural traffic impacts on soil. Journal of Terramechanics, v.42, p.259-280, 2005. 
REICHERT, J.M.; SUZUKI, L.E.A.S.; REINERT, D.J. Compactação do solo em sistemas agropecuários e florestais: identificação, efeitos, limites críticos e mitigação. In: CERETTA, C.A.; SILVA, L.S. da; REICHERT, J.M. (Org.). Tópicos em ciência do solo. Viçosa, Sociedade Brasileira de Ciência do Solo, 2007. v.5, p.49-134.

ROSA, D.P. da. Relação solo-máquina-planta num Argissolo cultivado e sob campo nativo. 2009. 109p. Tese (Doutorado) Universidade Federal de Santa Maria, Santa Maria.

ROSA, D.P. da; REICHERT, J.M.; SATTLER, A.; REINERT, D.J.; MENTGES, M.I.; VIEIRA, D.A. da. Relação entre solo e haste sulcadora de semeadora em Latossolo escarificado em diferentes épocas. Pesquisa Agropecuária Brasileira, v.43, p.395-400, 2008.

SANTOS, H.G. dos; JACOMINE, P.K.T.; ANJOS, L.H.C. dos; OLIVEIRA, V.A. de; OLIVEIRA, J.B. de; COELHO, M.R.; LUMBRERAS, J.F.; CUNHA, T.J.F. (Ed.). Sistema brasileiro de classificação de solos. 2.ed. Rio de Janeiro: Embrapa Solos, 2006. $306 \mathrm{p}$.

SAS INSTITUTE. SAS/STAT: user's guide. $4^{\text {th }}$ ed. Cary: SAS Institute, 1990.
SOANE, B.D.; OUWERKERK, C. van. Implications of soil compaction in crop production for the quality of the environment. Soil and Tillage Research, v.35, p.5-22, 1995.

SPOOR, G.; TIJINK, F.G.J.; WEISSKOPF, P. Subsoil compaction: risk, avoidance, identification and alleviation. Soil and Tillage Research, v.73, p.175-182, 2003.

STRECK, C.A.; REINERT, D.J.; REICHERT, J.M.; KAISER, D.R. Modificações em propriedades físicas com a compactação do solo causada pelo tráfego induzido de um trator em plantio direto. Ciência Rural, v.34, p.755-760, 2004.

TORMENA, C.A.; BARBOSA, M.C.; COSTA, A.C.S. da; GONÇALVES, C.A. Densidade, porosidade e resistência à penetração em Latossolo cultivado sob diferentes sistemas de preparo do solo. Scientia Agricola, v.59, p.795-801, 2002 .

TORMENA, C.A.; SILVA, A.P.; LIBARDI, P.L. Caracterização do intervalo hídrico ótimo de um Latossolo Roxo sob plantio direto. Revista Brasileira de Ciência do Solo, v.22, p.573-581, 1998.

Recebido em 7 de janeiro de 2011 e aprovado em 10 de dezembro de 2011 